\title{
Laboratory-confirmed invasive meningococcal disease: effect of the Hajj vaccination policy, Saudi Arabia, 1995 to 2011
}

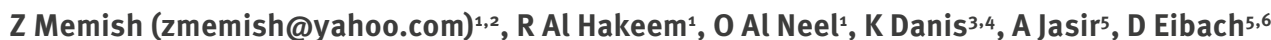

1. Public Health Directorate, WHO Collaborating Center for Mass Gathering Medicine, Ministry of Health, Riyadh, Kingdom of Saudi Arabia

2. College of Medicine, Alfaisal University, Riyadh, Kingdom of Saudi Arabia

3. European Programme Intervention Epidemiology Training (EPIET), European Centre for Disease Prevention and Control (ECDC), Stockholm, Sweden

4. Institut de Veille Sanitaire, Paris, France

5. European Public Health Microbiology Training Programme (EUPHEM), European Centre for Disease Prevention and Control (ECDC), Stockholm, Sweden

6. Centre de Biologie et Pathologie Est, Hospices Civils de Lyon, University of Lyon, Lyon, France

Citation style for this article:

Memish Z, Al Hakeem R, Al Neel O, Danis K, Jasir A, Eibach D. Laboratory-confirmed invasive meningococcal disease: effect of the Hajj vaccination policy, Saudi Arabia, 1995 to 2011. Euro Surveill. 2013;18(37):pii=20581. Available online: http://www.eurosurveillance.org/ViewArticle.aspx?Articleld=20581

Article submitted on 15 May 2013 / published on 12 September 2013

Saudi Arabia (SA) experienced two large invasive meningococcal disease (IMD) outbreaks during the 2000 and 2001 Hajj pilgrimages. In 2002, polysaccharide quadrivalent ACWY vaccines became mandatory for Mecca and Medina pilgrims/residents older than two years. This study aimed to analyse IMD surveillance data among citizens, residents and pilgrims in SA from 1995 to 2011, focusing on changes before and after the new vaccination policy. For all laboratory-confirmed IMD cases in the national surveillance database from 1995 to 2011, serogroup and age were retrieved. The cases' seasonal distribution as well as the case fatality ratios (CFR) were obtained. For Saudi citizens/residents and Hajj pilgrims, annual rates were calculated using mid-year population estimates. The Student's t-test was used to compare means between the pre-epidemic (1995-1999) and postepidemic (2002-2011) periods, excluding outbreak years. From 1995 to 2011, laboratories notified 1,103 cases. Between the pre- and post-epidemic periods, mean annual IMD rates decreased from 0.20 (standard deviation (SD): 0.1 ) to 0.06 cases/100,000 (SD: 0.06; $p=0.02$ ), mean numbers of Hajj-related cases from 13 (SD: 9.3) to 2 cases/year (SD: $2.3 ; p=0.02$ ) and the mean age from 31 (SD: 1.3) to 18 years (SD: 1.4; p<0.01). The CFR in Saudi citizens (10.4) was lower than among foreign pilgrims (28.9) and decreased from 19.3\% (SD: 1.8) in the pre-epidemic to $11.4 \%$ (SD: $7.0 ; p=0.04$ ) in the post-epidemic phase. The decrease of annual IMD rates, CFR and Hajj-related cases between the pre- and post- vaccine era suggests a possible positive effect of the mandatory ACWY vaccination for pilgrims/residents in Mecca and Medina. Regular surveillance with an annual data analysis is necessary to monitor trends and circulating serotypes and to implement appropriate public health measures to avoid new IMD epidemics during upcoming Hajj seasons.

\section{Introduction}

Invasive meningococcal disease (IMD) is caused by the gram-negative coccoid bacterium Neisseria meningitidis $[1,2]$. Transmission via respiratory droplets can lead to bacterial meningitis and septicaemia in the persons who get infected. Six serogroups (A, B, C, W135, $X$ and $Y$ ) differentiated by their polysaccharide capsule, account for the majority of IMD cases [3]. IMD primarily affects children below five years of age, causing an estimated 500,000 cases and 50,000 deaths annually worldwide [4]. Polysaccharide and conjugated vaccines are available for serogroups A, C, W135 and Y [5]. One vaccine for serogroup $B$ has been licensed in Europe in January 2013 and other serogroup B vaccines have been used in New Zealand, Cuba and France to control epidemics [6].

In Saudi Arabia (SA), the annual Hajj and the yearround Umrah pilgrimage lead to a particular high risk of outbreaks with invasive N. meningitidis. The Hajj pilgrimage is held on every 12th month of the Islamic calendar (2011 attendance: 2.9 million pilgrims, including 1.8 million from $>140$ foreign countries), making it one of the largest mass gathering events worldwide [7-9]. About 45,000 pilgrims arrive from the European Union each year [7]. Compared to the Hajj, the Umrah pilgrimage includes slightly different rituals and can be undertaken at any time of the year. Foreign pilgrims generally arrive by air in the city of Jeddah and continue to the pilgrimage sites in Mecca, Mina, Mount Arafat and Muzdalifah. Many end the journey with a visit to the holy sites in Medina [7]. Extreme congestion with populations from diverse geographical areas appears to promote a high prevalence of asymptomatic $N$. meningitidis carriage, with up to $80 \%$ reported for Mecca pilgrims $[10,11]$. In comparison carriage prevalence between $3 \%$ and $30 \%$ has been shown for the 
African meningitis belt and in a Norwegian randomised study, $9.6 \%$ of Norwegian volunteers harboured N. meningitidis $[12,13]$. The United States (US) Centers for Disease Control reported five to $10 \%$ of adults as asymptomatic nasopharyngeal carriers [14].

Following an outbreak of serogroup A IMD among pilgrims in 1987, Saudi Arabian health authorities implemented three interventions: (i) the compulsory vaccination before entering $S A$ with bivalent $A C$ vaccine for all Hajj pilgrims, (ii) annual vaccination campaigns for all residents in the proximity of pilgrimage sites and (iii) compulsory oral ciprofloxacin upon entering SA to pilgrims from sub-Saharan Africa to eradicate nasal carriage $[11,15,16]$.

In response to two large IMD outbreaks caused by N. meningitidis serogroup $\mathrm{W}_{135}$ in the 2000 and 2001 Hajj seasons $[15,17]$, the SA Ministry of Health $(\mathrm{MoH})$ adjusted their vaccination policy. In 2002, they required a polysaccharide quadrivalent non-conjugated ACWY meningococcal vaccine for (i) children and adults aged above two years living in Mecca and Medina, (ii) Hajj pilgrims aged above two years from within and outside of SA, (iii) healthcare workers in SA and (iv) government personnel serving the pilgrims [18]. Since 2010, a conjugated polysaccharide quadrivalent ACWY meningococcal vaccine is given to the same target groups aged from above two to 55 years. The vaccines are administered during annual vaccination campaigns in Mecca and Medina in a single dose with boosters every three years. As of 2013 no meningococcal vaccines are included in the SA national childhood immunisation schedule (NCIS). This study aims to describe the epidemiology of IMD in Saudi Arabia for the years 1995 to 2011, with a focus on changes in incidence and case fatality ratio (CFR) after the introduction of the polysaccharide quadrivalent ACWY vaccine in 2002, in order to evaluate the effect of this Hajj vaccination policy change.

\section{Methods}

A confirmed IMD case was defined as either isolation of $N$. meningitidis from cerebrospinal fluid (CSF) or blood or detection of capsular antigen in CSF by latex agglutination assay [19]. An IMD surveillance system was started in 1994 in SA based on recommendations of the World Health Organization (WHO) [20]. Since then, the Preventive Medicine Directorate at the $\mathrm{MoH}$ requires laboratories from all 20 health regions in $\mathrm{SA}$ to anonymously report confirmed IMD cases. The casebased reporting form collects information on age, sex, nationality, SA residency status, vaccination status, date of onset of symptoms (by Gregorian and Islamic calendar), clinical status and place of laboratory confirmation (health region). Information on the capsular groups, determined by latex agglutination, is also collected on the reporting form.

For the purposes of this study, all IMD cases in the surveillance database from 1 January 1995 to 31 December
2011 were extracted. This included cases among Saudi citizens and residents, foreign pilgrims and illegal immigrants. A citizen was considered a person in possession of the Saudi Arabian nationality, and a resident a person originating from outside SA but residing and working in SA. A foreign pilgrim was defined as a person holding a special visa for the Hajj or Umrah pilgrimage, whereas an illegal immigrant was an unregistered person devoid of any valid entry permit for SA. Hajj-related cases were specified as IMD cases with dates of disease onset during the Hajj season in the cities of Mecca or Medina.

\section{Statistical analysis}

Age group-, sex- and region-specific annual and cumulative disease incidences were calculated for IMD cases among Saudi citizens or residents. Age group- (0-4; $5-14 ; 15-64 ;>65$ years of age) and year-specific population denominators were obtained from the United Nations Development Programme (UNDP) website [21]. To calculate the cumulative incidence over several years, mid-period population estimates were used as a denominator. The Ministry of Hajj, Saudi Arabia [22] provided the numbers of foreign and domestic Hajj pilgrims. For foreign Hajj pilgrims, no age or sex specific incidences have been calculated, as no age or sex specific Hajj pilgrim numbers were available. In the absence of a population register to calculate rates, illegal immigrants were excluded from any incidence calculations.

From all cases, regardless of citizenship and nationality, numbers of Hajj-related IMD cases as well as year, age and region specific CFRs were calculated. Relative risks for death from IMD were identified by calculating ratios of case-fatalities and their $95 \%$ confidence intervals ( $95 \% \mathrm{Cls}$ ) for the residence status, seasons, age groups and sex. The Student's t-test was used to compare means (age, CFRs and number of cases) between the pre-epidemic (1995-1999) and post-epidemic (2002-2011) periods, excluding the outbreak years (years 2000, 2001), and linear regression models were fitted to describe trends. A p-value $<0.05$ was considered statistically significant. Surveillance data were computerised using Excel programme (Microsoft, USA) and statistical analysis was performed with Stata 12 (Statacorp, Texas, USA) software.

\section{Results}

\section{Study population}

During the study period, the population of SA rose from $18,491,845$ in 1995 to $27,448,000$ persons in 2011 , the latter of which comprises $68 \%$ SA citizens and $32 \%$ residents of foreign origin [21]. In 2011, children less than five years-old and adults above 65 years of age accounted for $10 \%$, and $3 \%$ of the population, respectively. The largest population increase has been recorded for the 15 to 64 years age group, which comprised $66.7 \%$ of the population in 2011 (compared to 56.1 in 1995). Forty-five percent of the population were 
Confirmed invasive meningococcal disease cases by residency status in Saudi Arabia, 1995-2011 ( $\mathrm{n}=1,103)$

\begin{tabular}{|c|c|c|c|c|c|c|}
\hline \multirow[b]{2}{*}{ Confirmed IMD cases ${ }^{a}$} & \multicolumn{6}{|c|}{ Residency status } \\
\hline & Citizen & Resident & $\begin{array}{l}\text { Visa-holding } \\
\text { Hajj pilgrim }\end{array}$ & $\begin{array}{l}\text { Visa-holding } \\
\text { Umrah pilgrim }\end{array}$ & Illegal & Unknown \\
\hline Male/female & $227 / 149$ & $181 / 88$ & $136 / 163$ & $54 / 19$ & $78 / 4$ & $3 / 1$ \\
\hline Mean age in years (SD) & $9.6(0.8)$ & $14.4(1.0)$ & $48.9(0.9)$ & $51.4(2.1)$ & $29.5(1.2)$ & $35(2.9)$ \\
\hline Number of deaths & 39 & 28 & 111 & 14 & 6 & 0 \\
\hline \multicolumn{7}{|l|}{ Time period } \\
\hline 1995-1999 & 78 & 61 & 60 & 46 & 18 & 2 \\
\hline $2000-2001$ & 193 & 179 & 223 & 26 & 31 & 2 \\
\hline $2002-2011$ & 105 & 29 & 16 & 1 & 33 & 0 \\
\hline \multicolumn{7}{|l|}{ Serogroup } \\
\hline Serogroup A & 36 & 45 & 63 & 30 & 18 & 1 \\
\hline Serogroup B & 33 & 7 & 22 & 2 & 2 & 0 \\
\hline Serogroup C & 5 & 2 & 0 & 2 & 1 & 0 \\
\hline Serogroup W135 & 153 & 99 & 110 & 4 & 9 & 0 \\
\hline Other serogroups & 11 & 1 & 0 & 0 & 0 & 0 \\
\hline Unknown serogroups & 138 & 115 & 104 & 35 & 52 & 3 \\
\hline Total confirmed IMD cases & 376 & 269 & 299 & 73 & 82 & 4 \\
\hline $\begin{array}{l}\text { Mid-period population } \\
\text { estimates }(1995-2011)^{b}\end{array}$ & \multicolumn{2}{|c|}{$22,652,297$} & $1,452,978$ & Unknown & Unknown & Unknown \\
\hline
\end{tabular}

IMD: invasive meningococcal disease; SD: standard deviation.

a Unless otherwise specified.

b For the period considered, only the number of citizens and residents combined are available. No reliable numbers for Umrah pilgrims and persons with illegal residency status are available.

female. There were $1,936,124$ and $1,858,490$ persons registered in the health districts of Mecca and Medina in 2011 respectively, representing $14 \%$ of the population in SA. During the study period the number of Hajj pilgrims increased by $57 \%$ from $1,865,234(1,080,465$ from outside SA) in 1995 to $2,927,717(1,828,195$ from outside SA) in 2011 [22].

Annual and cumulative invasive meningococcal disease incidences

Between 1995 and 2011, 1,103 cases of IMD were reported to the $\mathrm{MoH}$ in SA (Table 1). Of those, 645 cases were Saudi citizens/residents and 299 were foreign Hajj pilgrims. Of the remaining cases, 82 were illegal immigrants (not included in incidence calculations), 73 were foreign Umrah pilgrims and four had unknown identity (combined cumulative incidence of IMD among citizens, residents and foreign Hajj pilgrims: 3.92/100,000 population). Between 1995 and 1999, the mean annual incidence was $0.20 / 100,000$, ranging from $0.25 / 100,000$ in 1995 to $0.06 / 100,000$ in 1999 (Figure $1 \mathrm{~A}$ ). In the two outbreak years of 2000 and 2001, the annual incidence increased to 1.42 and $1.32 / 100,000$, respectively. In the post-epidemic period, the mean annual incidence did not exceed $0.06 / 100,000$, ranging from $0.21 / 100,000$ in 2002 to $0.01 / 100,000$ in 2010, a significant decrease compared to the pre-epidemic period $(p=0.02)$ (Figure $1 \mathrm{~A})$.
In an analysis restricted to SA citizens and residents, the cumulative incidence between 1995 and 2011 (2.85 cases $/ 100,000$ ) was lower compared to rates including Hajj pilgrims. Outside the outbreak periods the annual incidence followed the same trend described above (Figure 1A).

\section{Age, sex and region specific incidence for Saudi Arabia citizens and residents} For SA citizens and residents, in the study period, the age group including less than four year-olds had the highest cumulative incidence, with both sexes equally affected (12.3 cases/100,000; Figure 2). Above four years of age, males had a higher cumulative incidence. Among those between 15 and 64 years of age, cumulative incidence among males (1.8 cases/100,000) was three times higher than among females ( 0.6 cases/100,000).

In the period between 1995 and 2011, citizens and residents in the main Hajj pilgrimage destinations had a high cumulative incidence (Mecca: 9.04 cases/100,000 $\mathrm{n}=175$; Medina: 4.52 cases $/ 100,000 \mathrm{n}=84$ and Jeddah: 2.28 cases $/ 100,000 \mathrm{n}=88$ ), whereas urban regions, not visited by the Hajj pilgrims, such as the capital city Riyadh ( 1.85 cases $/ 100,000 \mathrm{n}=131)$ had lower cumulative incidences. 


\section{FIGURE 1}

Annual incidence of invasive meningococcal disease (panel A) and distribution of invasive meningococcal disease cases linked to the Hajj (panel B), Saudi Arabia, 1995-2011
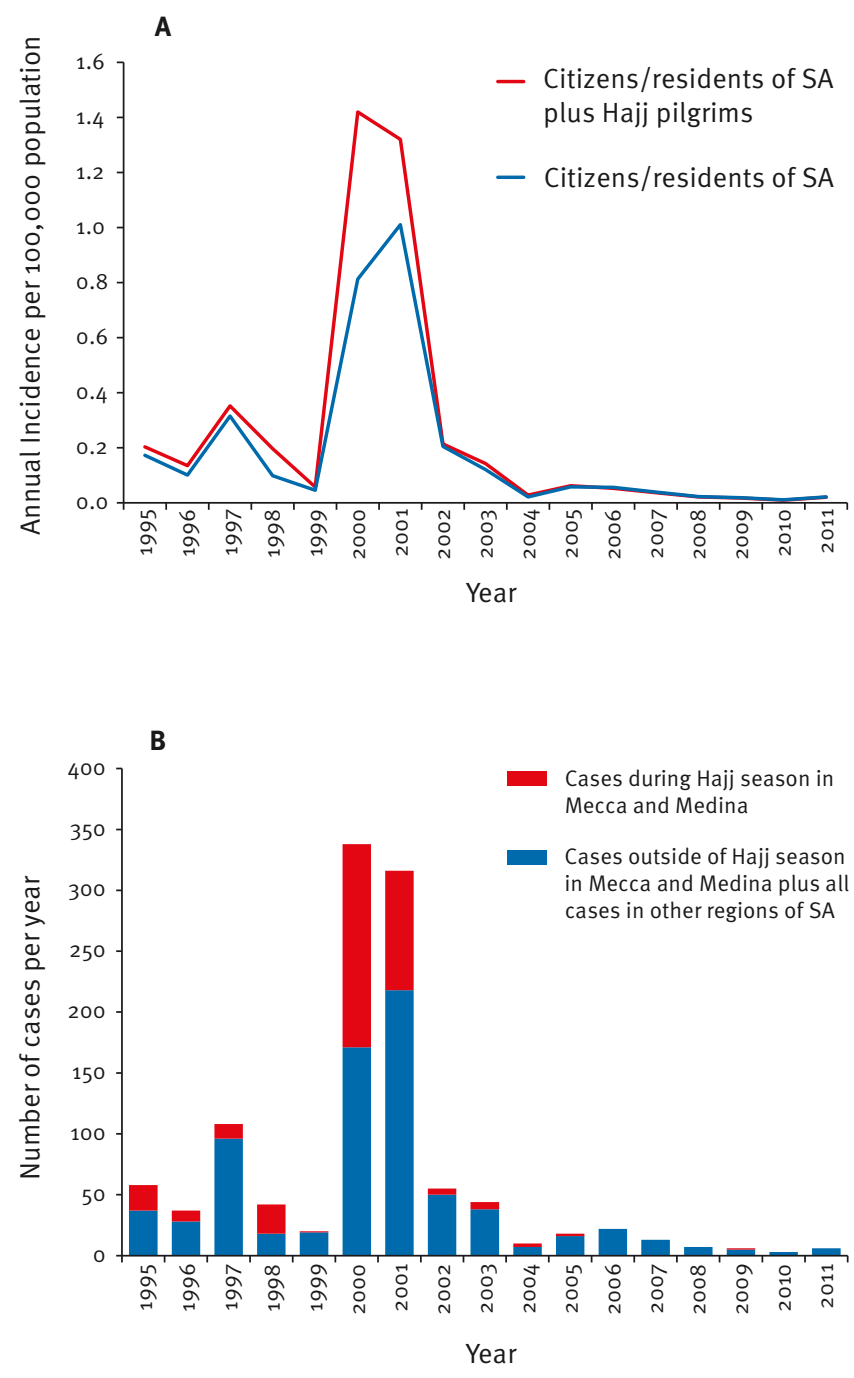

SA: Saudi Arabia.

\section{FIGURE 2}

Cumulative incidence of invasive meningococcal disease for citizens and residents of Saudi Arabia by age group and sex, 1995-2011 $(\mathrm{n}=645)$

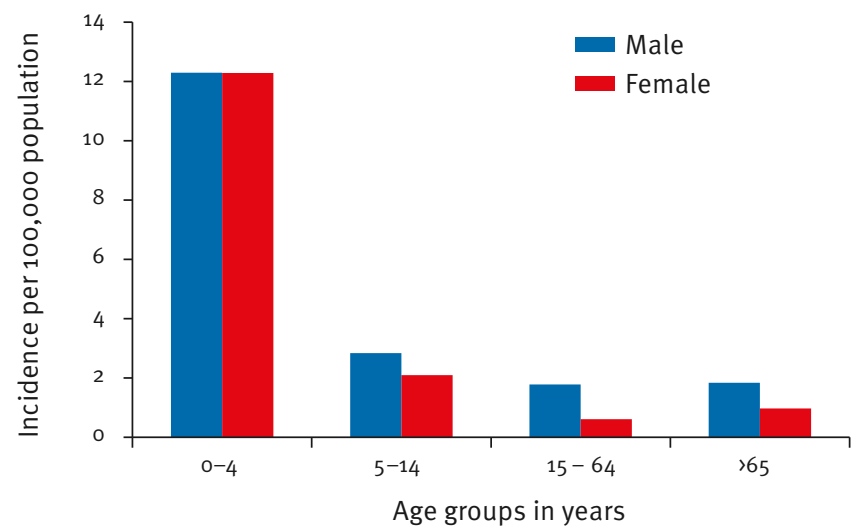

Hajj-related cases

In the 2000 and 2001 outbreak years, IMD cases from Mecca and Medina during the Hajj accounted for $49 \%$ and $31 \%$ of all notified annual IMD cases, respectively (Figure 1B). In contrast, between 2002 and 2011, only a mean annual $8.1 \%$ (standard deviation (SD): 10.1) of all IMD cases were reported from Mecca or Medina during the Hajj season. Since 2006, during Hajj seasons, Medina reported only one case of IMD. The mean numbers of Hajj-related cases was higher (13.4 cases/year; SD: 9.3) during the pre-epidemic than during the postepidemic years (1.7 cases/year; SD: 2.3; $p=0.02$ ).

\section{Distribution of mean age}

In the period between 1995 and 2011, among SA citizens and residents, the age group comprising those younger than four years had the highest disease incidence. However, the mean age of all IMD cases, including pilgrims, between 1995 and 2011 was 25.8 (SD: 0.7 ) years. The mean age decreased from 31 years (SD: 1.3) in the pre-epidemic period to 18 years (SD: 1.4 ) in the post-epidemic period ( $p<0.01$; b coefficient -1.27 , Figure 3).

The mean age of IMD cases during the Hajj season (37.0 years; SD: 1.0) was higher ( $p$ ro.01) than among cases outside this season (17.4 years; SD: 0.8 ). Similarly, the mean age of IMD cases among foreign Hajj and Umrah pilgrims (48.9 (SD: 0.9); 51.4 (SD: 2.1), respectively) was higher ( $p<0.01)$ than among SA residents cases (14.4 years; SD: 1.0 ) or citizens (9.6 years; SD: 0.8). Finally, cases in Mecca (33.9 years; SD: 1.2) and Medina (31.4 years; SD: 1.8 ) had a higher mean age than in other health regions (16.7 years; SD: 0.8 ) (p<0.01).

\section{Serogroup distribution}

Serogroup results were available for $59 \%(656 / 1,103)$ of all cases reported between 1995 and 2011. In 33\% $(369 / 1,103)$ the serogroup could not be determined and in $7 \%(78 / 1,103)$ no information was submitted (Table 2). In one isolate, serogroups $A$ and $C$ and in nine isolates serogroups $A, C, W_{135}$ and $Y$ were not further subtyped. Of all serogrouped isolates, $89 \%(587 / 656)$ belonged to the vaccine preventable serogroups $A, C$, $\mathrm{W}_{135}$ and Y. From 1995 to 1999 , the predominant serogroup was A, accounting for $49 \%$ (77/158) of all typed isolates, followed by B with $26 \%(41 / 158)$ and serogroup W135 with $20 \%$ (31/158) of isolates (Table 2). During the 2000 and 2001 outbreak years, the emerging serogroup $W_{135}$ predominated, accounting for $78 \%$ (298/383) of typed isolates, while during the postepidemic period between 2002 and 2011, serogroups $\mathrm{A}$ and W135 were almost equally distributed (36\% (41/115) and 40\% (46/115), respectively), while serogroup B accounted for $17 \%$ (19/115) of typed isolates.

The age group below one year is dominated by isolates of serogroup B (19\% (14/74)) and serogroup W 135 (70\% $(52 / 74))$. In those aged one through four years, serogroup W135 is by far the most common serogroup ( $78 \%$ 


\section{TABLE 2}

Distribution of serogroups for all typed isolates $(n=656)$ among invasive meningococcal disease cases $(n=1,103)$ and stratification by time periods, age groups, and outcome, Saudi Arabia

\begin{tabular}{|c|c|c|c|c|c|c|c|c|}
\hline \multirow{2}{*}{ Confirmed IMD cases } & \multicolumn{8}{|c|}{ Serogroups } \\
\hline & A & B & C & W135 & $x$ & $\mathrm{Y}$ & Z & Total \\
\hline \multicolumn{9}{|l|}{ Time period } \\
\hline $2000-2001^{\mathrm{b}} \mathrm{n}(\%)$ & $75(20)$ & $6(2)$ & $4(1)$ & $298(78)$ & $0(0)$ & $0(0)$ & $0(0)$ & 383 \\
\hline $\left.2002-2012^{c} n \%\right)$ & $41(36)$ & $19(17)$ & $0(0)$ & $46(40)$ & $2(2)$ & $6(5)$ & $1(1)$ & 115 \\
\hline \multicolumn{9}{|l|}{ Age groups } \\
\hline «1 year $\mathrm{n}(\%)$ & $4(5)$ & $14(19)$ & $1(1)$ & $52(70)$ & $1(1)$ & $2(3)$ & $0(0)$ & 74 \\
\hline $1-4$ years n(\%) & $15(10)$ & $12(8)$ & $3(2)$ & $112(78)$ & $0(0)$ & $1(1)$ & $0(0)$ & 143 \\
\hline 5-14 years $n(\%)$ & $25(29)$ & $4(5)$ & $1(1)$ & $51(59)$ & $0(0)$ & $4(5)$ & $1(1)$ & 86 \\
\hline $15-45$ years $n(\%)$ & $82(43)$ & $21(11)$ & $2(1)$ & $81(43)$ & $1(0)$ & $2(1)$ & $0(0)$ & 189 \\
\hline$>45$ years n(\%) & $67(41)$ & $15(9)$ & $3(2)$ & $79(48)$ & $0(0)$ & $0(0)$ & $0(0)$ & 164 \\
\hline Deaths & 42 & 14 & 2 & 74 & 0 & 3 & 0 & 135 \\
\hline CFR $^{d}(\%)$ & 21.8 & 21.2 & 20 & 19.7 & 0.0 & 33.3 & 0.0 & 20.6 \\
\hline
\end{tabular}

CFR: case fatality ratio; IMD: invasive meningococcal disease.

Of 1,103 isolates from cases of invasive meningococcal disease 369 isolates were not typable and for 78 isolates serogroups were not reported. The CFR for cases with untypable isolates was $9.8 \%$ (36 deaths).

a Pre-epidemic period.

b Epidemic period.

c Post-epidemic period.

d CFR=Deaths/total number of confirmed IMD cases.

\section{FIGURE 3}

Mean age of invasive meningococcal disease cases, Saudi Arabia, 1995-2011 (n=1,103)

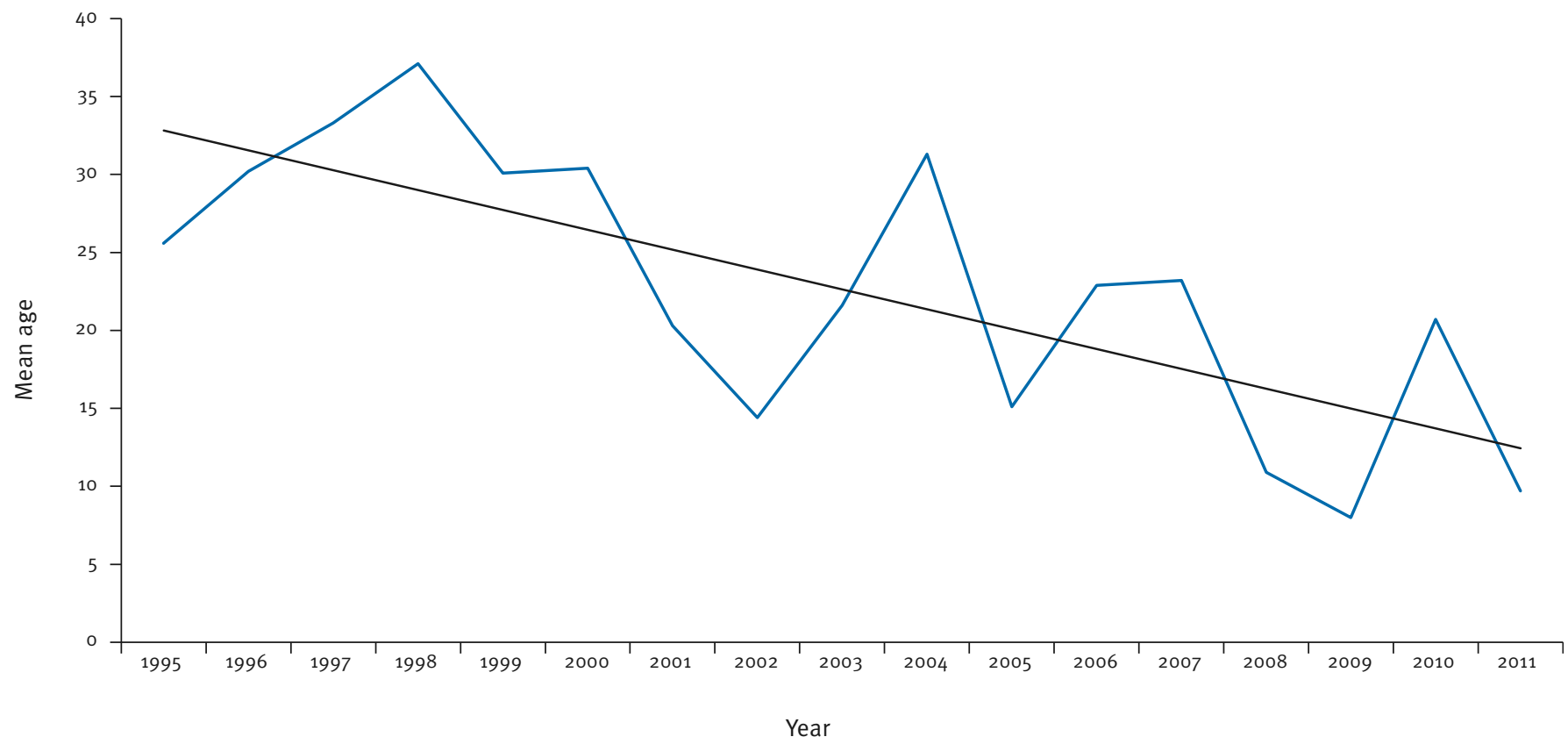

The black line can be expressed by the equation $y=34.108-1.2747 x ;\left(R^{2}=0.54\right)$.

The mean age of invasive meningococcal disease cases was 31 years (standard deviation (SD): 1.3) in the pre-epidemic period (1995-1999) and 18 years (SD: 1.4) in the post-epidemic period (2002-2011). 


\section{TABLE 3}

Mortality, case fatality ratio and relative risk of dying from invasive meningococcal disease by residency status, Hajj season, age group and sex, Saudi Arabia, 1995-2011 ( $\mathrm{n}=1,103)$

\begin{tabular}{|c|c|c|c|c|c|}
\hline Characteristics & Number of deaths & CFR (\%) & Relative Risk ${ }^{b}$ & $95 \% \mathrm{Cl}$ & $p$-value \\
\hline \multicolumn{6}{|c|}{ Saudi citizen/resident } \\
\hline Yes & 67 & 10.39 & 1.00 (reference) & NA & NA \\
\hline No & 131 & 28.85 & 2.78 & $2.12-3.63$ & $<0.01$ \\
\hline \multicolumn{6}{|l|}{ Hajj season } \\
\hline Yes & 135 & 28.60 & 2.86 & $2.18-3.77$ & $<0.01$ \\
\hline No & 63 & 9.98 & 1.00 (reference) & NA & NA \\
\hline \multicolumn{6}{|l|}{ Age group } \\
\hline$\ll 1$ year & 8 & 6.84 & 1.00 (reference) & NA & NA \\
\hline $1-4$ years & 20 & $9 \cdot 35$ & 1.37 & $0.62-3.01$ & 0.43 \\
\hline $5-14$ years & 13 & 9.29 & 1.36 & $0.58-3.16$ & 0.48 \\
\hline $15-45$ years & 72 & $19 \cdot 41$ & 2.84 & $1.41-5 \cdot 72$ & 0.01 \\
\hline \multicolumn{6}{|l|}{ Sex } \\
\hline Male & 117 & 17.23 & 0.90 & $0.70-1.17$ & 0.43 \\
\hline Female & 81 & 19.10 & 1.00 (reference) & NA & NA \\
\hline
\end{tabular}

CFR: case fatality ratio; $\mathrm{Cl}$ : confidence interval; NA: not applicable.

a $C F R=$ (Number of deaths / Number of confirmed IMD cases) in each category.

b The relative risk of dying from invasive meningococcal disease is calculated by dividing the CFR of the relevant row by the CFR of the reference row.

(112/143)) among typed isolates. Above four years of age, serogroups $A$ and $W_{135}$ comprise $87 \%$ (385/439) of all typed isolates in those age groups. Serogroups other than A, B and W135 contribute only marginally to the IMD burden in SA (Table 2).

\section{Case fatality}

Between 1995 and 2011, the overall reported CFR was $18.0 \%(198 / 1,103)$, with a decrease from an annual mean of $19.3 \%$ (SD: 1.8 ) in the pre-epidemic years to $11.4 \%$ (SD: 7.0$)$ in the post-epidemic years $(p=0.04)$. The CFR increased with age, from $6.8 \%$ in the 11 yearolds to $32.6 \%$ in the $>45$ years age group (Table 3 ). When stratified by age groups, no significant changes in the CFR for the 45 years group between pre-epidemic (13.6\%; 95\% Cl: $0.0-39.6)$, epidemic $(6.3 \% ; 95 \% \mathrm{Cl}$ : $0.0-40.6)$ and post-epidemic years $(12.4 \% ; 95 \% \mathrm{Cl}$ : 3.2-21.6) were observed (Table 4). For cases $>5$ years of age, the CFR decreased significantly between the pre-epidemic $(20.72 \% ; 95 \% \mathrm{Cl}: 18.2-23.2)$ and postepidemic period $(8.72 \% ; 95 \% \mathrm{Cl}: 2.6-14.8)$. During the epidemic the CFR for cases above five years-old was significantly elevated $(25.6 ; 95 \% \mathrm{Cl}: 24.9-26.2)$. The CFR was similar for the most common serogroups ( $A$ : 21.8\%; B: 21.2\%; C: $20.0 \%$; W135: 19.7\%). Among Hajj or Umrah pilgrims from foreign countries the CFR was 2.8 times higher than Saudi citizens/residents (Table $3)$. In addition, the CFR during the Hajj season (28.6\%) was 2.9 times higher than outside the season (10.0\%).

\section{Discussion}

According to the present study and confirming previous reports, the Hajj season constitutes a special opportunity that is very favourable to IMD epidemics $[7,9,10]$. The high morbidity and fatality for pilgrims during the Hajj season might be largely explained by epidemiologically unfavourable conditions (e.g. crowding, delayed clinical and laboratory diagnosis). Our study indicates that the incidence of IMD decreased in SA following the introduction of the ACWY vaccine in 2002. More specifically, Hajj-related IMD cases declined after the introduction of the vaccine compared to pre-epidemic years. The results suggest that the compulsory use of the ACWY vaccine for pilgrims and residents of Mecca and Medina may have played a role in reducing not only Hajj-related IMD cases, but also the overall disease incidence in SA.

Children under five, predominantly affected by serogroup $B$ and $W_{135}$ infections, suffered the highest agespecific incidence of IMD throughout the study period. This is consistent with experience from the United Kingdom (UK), the US and Germany, where $B$ is the most prevalent serogroup in children below five years [23-25]. The mean age of cases decreased during the study period. Two factors may explain this evolution. First, there could have been a decrease in IMD in adolescent or adult Hajj pilgrims since 2002 because of the vaccine introduction for all Hajj pilgrims. Second, 
TABLE 4

Annual mean case fatality ratio (CFR) by age groups, Saudi Arabia, 1995-2011

\begin{tabular}{|l|c|c|c|}
\hline \multirow{2}{*}{ Age group } & \multicolumn{3}{|c|}{ Mean of the annual CFR $(95 \% \mathrm{Cl})$} \\
\cline { 2 - 4 } & $1995-1999$ & $2000-2001$ & $2002-2011$ \\
\hline$<5$ years-old & $13.64(0.00-39.56)$ & $6.30(0.00-40.61)$ & $12.4(3.21-21.59)$ \\
\hline$\geq 5$ years-old & $20.72(18.24-23.20)$ & $25.55(24.91-26.19)$ & $8.72(2.62-14.82)$ \\
\hline
\end{tabular}

$95 \% \mathrm{Cl}: 95 \%$ confidence interval.

a $C F R=$ (Number of deaths /Number of confirmed IMD cases) in each category.

no meningococcal vaccines are yet given to children below three years-old according to the Hajj vaccination policy from 2002.

The CFR of IMD was highest among older age groups, as reported elsewhere $[23,26]$. Our data indicate that one third of deaths occurred among persons $>45$ years of age. Following introduction of ACWY meningococcal vaccine, both the IMD morbidity and the CFR for above four year-olds decreased among the SA population including Hajj pilgrims. A number of factors could be responsible for this finding. First, the reduced number of cases among pilgrims during the Hajj season in recent years contribute to a lower CFR, as clinical and laboratory diagnosis might be delayed during the Hajj and pilgrims seek medical care too late while being on the pilgrimage. Second, the reduction in the mean age of cases might contribute to the decreased CFR and third, there might have been increased awareness after the two outbreak years 2000 and 2001 leading to a more rapid diagnosis and therefore improved healthcare measures. The reported CFR outside of the Hajj season $(10 \%$, and $11 \%$ for the whole post-vaccination period) were comparable to reports from non-endemic European countries. Austria, France, Germany, UK reported CFRs ranging from 8.2 to $12.5 \%$ [24,25, 27-29].

The reported mean annual incidence of IMD for citizen, residents and Hajj pilgrims in SA during the postepidemic period was low. The US reported 0.35 IMD cases/100,000 in 2007, New Zealand 2.6 cases/100,000 in 2007 and Taiwan 0.2 cases/100,000 in 2001 [10]. The European Invasive Bacterial Infection Surveillance (EU-IBIS) project reported 1.01 cases/100,000 in 2006 from 27 European countries [10]. However, those incidence rates cannot be compared to those in SA, as the serogroup distribution in those countries differs, which changes the disease impact completely. Differences in case definitions, which include different laboratory methods as well as clinical and epidemiological criteria, impede international comparisons, as examples from European and Australian guidelines illustrate $[30,31]$. In the future, introduction of new sensitive polymerase chain reaction (PCR) methods for the detection of $N$. meningitidis in SA, could enable laboratories to confirm a higher number of suspected IMD cases $[32,33]$.

In the current IMD surveillance database, it proved difficult to distinguish between $\mathrm{Hajj}$ related cases and non-Hajj cases. We used the time of disease onset and the region to infer a potential connection to the pilgrimage. As per our criteria, cases outside of Mecca and Medina with contact to Hajj pilgrims, or Hajj pilgrims moving outside both cities, would not be identified as Hajj-related. As this information could be used to implement public health control measures, reporting health personnel should verify the Hajj-related status of every case.

The majority of outbreak-related cases were caused by $N$. meningitidis serogroup $W_{135}$. The responsible clone was later found to belong to the ST-11/ET-37 complex [34]. Genetic analysis of the clone suggested that a capsular switch from serogroup $C$ to serogroup W135 may have occurred years before the onset of the outbreak [34]. The same hypervirulent clone caused serogroup C disease in Belgium, Iceland, Ireland, the Netherlands, Portugal and the UK in the late 1990s and early 2000 s [10]. Concerns had been raised that mass immunisation with vaccines that do not protect against all serogroups could lead to an increase in incidence of meningococcal disease due to strains not included in the vaccine $[35,36]$. Following the introduction of ACWY vaccines, this phenomenon of serotype replacement, or a major emergence of non-vaccine serotypes, has not been reported in Mecca and Medina, or elsewhere.

Vaccine coverage data are needed to determine whether the vaccine contributed to reduced morbidity. While no coverage data are available for foreign Hajj pilgrims, the entry requirement that is enforced through border checks suggest that coverage should be high. In comparison, compliance among Saudi pilgrims may be poorer, since Saudi citizens do not have to provide proof of vaccination at border controls or check points. In 2006, a study of 134 British and 109 Saudi Hajj pilgrims reported that vaccine coverage was lower among local residents (64\%) than among British pilgrims (100\%) [37]. According to this study, $50 \%$ of local pilgrims residing in Mecca and Jeddah had been 
vaccinated, compared with $71 \%$ from the rest of the country. Overall, a larger vaccine coverage study would obviously help interpret results of IMD surveillance data.

\section{Conclusion}

Saudi-Arabian IMD surveillance data highlight the shift from Hajj-related cases towards non-Hajj related ones, following the introduction of the ACYW vaccine in 2002. The number of cases and the CFR also declined, suggesting a potential positive effect of the current Hajj vaccination policy, among other factors. On the basis of our investigations, we can formulate a number of recommendations. First, regular monitoring of vaccination coverage would help interpret trends of IMD. Second, the surveillance system could be improved through notification of clinically suspected and epidemiologically-linked cases as well as including more sensitive molecular biology based diagnostic methods. Third, inclusion of information on possible links to the Hajj could be considered for the surveillance form. Continued surveillance with annual data analysis remains necessary to drive adapted public health measures and avoid future IMD epidemics during the Hajj seasons of the coming years.

\section{Acknowledgements}

We wish to acknowledge Yvan Hutin for his contribution to critical review of the manuscript.

Novartis vaccine and diagnostic provided financial support (including travel, transportation and accommodation, meals expenses) for the mission of EUPHEM fellow Daniel Eibach to the Kingdom of Saudi Arabia. The salary for the EUPHEM fellow is supported by a grant from ECDC and he did not receive any salary or honorariums from other sources. Novartis has not been involved in the study design, analysis, or writing of the paper nor has it influenced the analyses or results of the study.

\section{Conflict of interest}

None declared.

\section{Authors' contribution}

All authors contributed to the drafting, writing, and reviewing the manuscript.
References

1. Visintin C, Mugglestone MA, Fields EJ, Jacklin P, Murphy MS, Pollard AJ et al. Management of bacterial meningitis and meningococcal septicaemia in children and young people: summary of NICE guidance. BMJ. 2010;340:C3209. http:// dx.doi.org/10.1136/bmj.c3209. PMid:20584794.

2. Pollard AJ, Nadel S, Ninis N, Faust SN, Levin M. Emergency management of meningococcal disease: eight years on. Arch Dis Child. 2007;92(4):283-6. http://dx.doi.org/10.1136/ adc.2006.102384. PMid:17376933. PMCid:PMC2083684.

3. Chang Q, Tzeng YL, Stephens DS. Meningococcal disease: changes in epidemiology and prevention. Clin Epidemiol. 2012;4:237-45. PMid:23071402. PMCid:PMC3470458.

4. Wilder-Smith A. Meningococcal vaccine in travelers. Curr Opin Infect Dis. 2007;20(5):454-60. http://dx.doi.org/10.1097/ QC0.ob013e3282a64700. PMid:17762777.

5. Vipond C, Care R, Feavers IM. History of meningococcal vaccines and their serological correlates of protection. Vaccine. 2012;30 Suppl 2:B10-7. http://dx.doi.org/10.1016/j. vaccine.2011.12.060. PMid:22607894.

6. World Health Organization. Global Advisory Committee on Vaccine Safety, 12-13 December 2007. Wkly Epidemiol. Rec. 2008;83(4):37-44. PMid:18219807.

7. Ahmed QA, Arabi YM, Memish ZA. Health risks at the Hajj. Lancet. 2006;367(9515):1008-15. http://dx.doi.org/10.1016/ S0140-6736(06)68429-8

8. Aguilera JF, Perrocheau A, Meffre C, Hahné S; W135 Working Group. Outbreak of serogroup W135 meningococcal disease after the Hajj pilgrimage, Europe, 2000. Emerg Infect Dis. 2002;8(8):761-7. http://dx.doi.org/10.3201/eido808.010422. PMCid:PMC 2732506.

9. Memish ZA. Meningococcal disease and travel. Clin Infect Dis. 2002;34(1): 84-90. http://dx.doi.org/10.1086/323403. PMid:11731951.

10. Harrison LH, Trotter CL, Ramsay ME. Global epidemiology of meningococcal disease. Vaccine. 2009; 27 Suppl 2:B5163. http://dx.doi.org/10.1016/j.vaccine.2009.04.063. PMid:19477562.

11. al-Gahtani YM, el Bushra HE, al-Qarawi SM, al-Zubaidi AA, Fontaine RE. Epidemiological investigation of an outbreak of meningococcal meningitis in Makkah (Mecca), Saudi Arabia, 1992. Epidemiol Infect. 1995;115(3):399-409. http:// dx.doi.org/10.1017/S0950268800058556. PMid:8557071. PMCid:PMC 2271597.

12. Trotter CL, Greenwood BM. Meningococcal carriage in the African meningitis belt. Lancet Infect Dis. 2007;7(12):797-803. http://dx.doi.org/10.1016/S1473-3099(07)70288-8

13. Caugant DA, Høiby EA, Magnus P, Scheel O, Hoel T, Bjune G et al. Asymptomatic carriage of Neisseria meningitidis in a randomly sampled population. J Clin Microbiol. 1994;32(2):32330. PMid:8150942. PMCid:PMC 263032.

14. Centers for Disease Control and Prevention (CDC). VPD Surveillance Manual, 5th Edition, Atlanta; CDC; 2011. Chapter 8, Meningococcal Disease. [Accessed og Aug 2013]. Available from: http://www.cdc.gov/vaccines/pubs/surv-manual/chpto8mening.pdf

15. Memish ZA, Venkatesh S, Ahmed QA. Travel epidemiology: the Saudi perspective. Int J Antimicrob Agents. 2003;21(2): 96-101. http://dx.doi.org/10.1016/S0924-8579(02)00364-3

16. Wilder-Smith A, Memish Z. Meningococcal disease and travel. Int J Antimicrob Agents. 2003;21(2):102-6. http://dx.doi. org/10.1016/So924-8579(02)00284-4

17. Al-Mazrou YY, Al-Jeffri MH, Abdalla MN, Elgizouli SA, Mishskas AA. Changes in epidemiological pattern of Meningococcal disease in Saudi Arabia. Does it constitute a new challenge for prevention and control? Saudi Med J. 2004;25(10):1410-3. PMid:15494812.

18. World Health Organization. Health conditions for travellers to Saudi Arabia pilgrimage to Mecca (Haji). Wkly Epidemiol Rec. 2005;80(49-50):431-2. PMid:16372666.

19. Olcén $P$, Fredlund $H$. Isolation and characterization of Neisseria meningitidis in the vaccine era. Who needs what and when? Scand J Infect Dis. 2010;42(1):4-11. http://dx.doi. org/10.3109/00365540903311177. PMid:19883161.

20. World Health Organization (WHO). Control of epidemic meningococcal disease. WHO practical guidelines. 2nd edition. Geneva: WHO; 1998.

21. United Nations Development Programme (UNDP). International Human Development Indicators. New York: UNPD. [Accessed 29 Jan 2013]. Available from: http://hdr.undp.org/en/statistics/

22. Ministry of Hajj, Kingdom of Saudi Arabia. [Accessed 10 Sep 2013]. Available from: http://www.hajinformation.com 
23. Harrison LH, Pass MA, Mendelsohn AB, Egri M, Rosenstein NE, Bustamante A, et al. Invasive meningococcal disease in adolescents and young adults. JAMA. 2001;286(6):694-9. http://dx.doi.org/10.1001/jama.286.6.694. PMid:11495619.

24. Shigematsu M, Davison KL, Charlett A, Crowcroft NS.

National enhanced surveillance of meningococcal disease in England, Wales and Northern Ireland, January 1999June 2001. Epidemiol Infect. 2002;129(3):459-70. http:// dx.doi.org/10.1017/S0950268802007549. PMid:12558328. PMCid:PMC2869907.

25. Robert Koch Institut (RKI). Invasive MeningokokkenErkrankungen im Jahr 2007. Epidemiologisches Bulletin. 2008;32:265-72. German.

26. Ladhani SN, Flood IS, Ramsay ME, Campbell H, Gray SJ, Kaczmarski EB, et al. Invasive meningococcal disease in England and Wales: implications for the introduction of new vaccines. Vaccine. 2012;30(24):3710-6. http://dx.doi. org/10.1016/j.vaccine.2012.03.011. PMid:22429756.

27. Olivares R, Bouyer J, Hubert B. Risk factors for death in meningococcal disease. Pathol Biol (Paris). 1993;41(2):164-8.

28. Steindl G, Liu YL, Schmid D, Orendi U, Kormann-Klement A, Heuberger S. Epidemiology of invasive meningococcal disease in Austria 2010. Wien Klin Wochenschr. 2011;123 Suppl 1:10-4. http://dx.doi.org/10.1007/s00508-011-0058-0. PMid:21935643.

29. Connolly M, Noah N. Is group C meningococcal disease increasing in Europe? A report of surveillance of meningococcal infection in Europe 1993-6. European Meningitis Surveillance Group. Epidemiol Infect. 1999;122(1):41-9. http://dx.doi. org/10.1017/S0950268898001848. PMid:10098784. PMCid:PMC 2809586.

30. European Centre for Disease Prevention and Control (ECDC). Case definitions. 2008 EU Case Definition (2008/426/EC) for meningococcal disease, invasive. Stockholm: ECDC. [Accessed 29 Jun 2013]. Available from: http://www.ecdc.europa.eu/en/ activities/surveillance/EU_IBD/Pages/Case_definition.aspx

31. Australian Government, Department of Health and Ageing. Australian national notifiable diseases case definitions. Meningococcal disease (invasive) surveillance case definition V1.4. Canberra: Australian Government, Department of Health and Ageing. [Accessed 29 Jun 2013]. Available from: http:// www.health.gov.au/internet/main/publishing.nsf/Content/cdasurveil-nndss-casedefs-cd_mening.htm

32. Ni H, Knight Al, Cartwright K, Palmer WH, McFadden J. Polymerase chain reaction for diagnosis of meningococcal meningitis. Lancet. 1992;340(8833):1432-4. http://dx.doi. org/10.1016/0140-6736(92)92622-M

33. Corless CE, Guiver M, Borrow R, Edwards-Jones V, Fox AJ, Kaczmarski EB. Simultaneous Detection of Neisseria meningitidis, Haemophilus influenzae, and Streptococcus pneumoniae in Suspected Cases of Meningitis and Septicemia Using Real-Time PCR. I Clin Microbiol. 2001;39(4):15538. http://dx.doi.org/10.1128/JCM.39.4.1553-1558.2001. PMid:11283086. PMCid:PMC87969.

34. Wilder-Smith A, Goh KT, Barkham T, Paton NI. Haji-associated outbreak strain of Neisseria meningitidis serogroup W135: estimates of the attack rate in a defined population and the risk of invasive disease developing in carriers. Clin Infect Dis. 2003;36(6):679-83. http://dx.doi.org/10.1086/367858. PMid:12627350.

35. Swartley JS, Marfin AA, Edupuganti S, Liu LJ, Cieslak P, Perkins $B$, et al. Capsule switching of Neisseria meningitidis. Proc Natl Acad Sci USA. 1997;94(1):271-6. http://dx.doi.org/10.1073/ pnas.94.1.271. PMid:8990198. PMCid:PMC19312.

36. Vogel U, Claus H, Frosch M. Rapid serogroup switching in Neisseria meningitidis. N Engl J Med. 2000;342(3):219-20. http://dx.doi.org/10.1056/NEJM200001203420319. PMid:10651563.

37. El Bashir H, Rashid H, Memish ZA, Shafi S; Health at Hajj and Umra Research group. Meningococcal vaccine coverage in Hajj pilgrims. Lancet. 2007;369(9570):1343. http://dx.doi. org/10.1016/S0140-6736(07)60625-4 